\title{
Effect of exercise on cardiac autonomic function in females with rheumatoid arthritis
}

\author{
Dina C. Janse van Rensburg • James A Ker • \\ Catharina C Grant • Lizelle Fletcher
}

Received: 2 December 2011 /Revised: 5 March 2012 / Accepted: 30 March 2012 / Published online: 19 April 2012

(C) The Author(s) 2012. This article is published with open access at Springerlink.com

\begin{abstract}
The objective of this study is to evaluate the effect of exercise on cardiac autonomic function as measured by short-term heart rate variability (HRV) in females suffering from rheumatoid arthritis (RA). Females with confirmed RA were randomly assigned to an exercise group (RAE) and a sedentary group (RAC). RAE was required to train under supervision two to three times per week, for 3 months. Three techniques (time domain, frequency domain and Poincaré plot analyses) were used to measure $\mathrm{HRV}$ at baseline and study completion. At baseline, RAC $(n=18)$ had a significantly higher variability compared to RAE $(n=19)$ for most HRV indicators. At study completion, the variables showing significant changes ( $p=0.01$ to 0.05 ) favoured RAE in all instances. Wilcoxon signed rank tests were performed to assess changes within groups from start to end. RAE showed significant improvement for most of the standing variables, including measurements of combined autonomic influence, e.g. SDRR $(p=0.002)$ and variables indicating only vagal influence, e.g. pNN50 $(p=0.014)$. RAC mostly deteriorated with emphasis on variables measuring vagal influence (RMSSD, pNN50, SD1 and HF $\left.\left(\mathrm{ms}^{2}\right)\right)$. Study results indicated that 12 weeks of exercise intervention had a positive effect on cardiac autonomic function as measured by short-term HRV, in females with
\end{abstract}

D. C. Janse van Rensburg $(\bowtie) \cdot$ C. C. Grant Section Sports Medicine, University of Pretoria, P O Box 12651, Hatfield, 0028 Pretoria, South Africa e-mail: christa.jansevanrensburg@up.ac.za

\section{J. A. Ker}

Department of Internal Medicine, University of Pretoria, Pretoria, South Africa

\section{Fletcher}

Department of Statistics, University of Pretoria, Pretoria, South Africa
RA. Several of the standing variables indicated improved vagal influence on the heart rate. Exercise can thus potentially be used as an instrument to improve cardiac health in a patient group known for increased cardiac morbidity.

Keywords Autonomic function $\cdot$ Exercise $\cdot$ Heart rate variability $\cdot$ Rheumatoid arthritis

\section{Introduction}

Rheumatoid arthritis (RA) patients are usually sedentary, limiting physical activity due to the perceived danger of eliciting pain or damaging their joints [1]. Although there is still no cure for RA, much can be done to manage the condition. There is compelling evidence that exercise can play a significant role in the physical and psychosocial health of RA patients $[2,3]$. However, only a limited number of studies exist on the relation of exercise interventions to cardiovascular disease in these patients [4].

Cardiovascular disease is a well-described entity in RA patients [5-7]. Conventional risk factors (abnormal body mass index (BMI), abnormal lipogram, smoking, hypertension, diabetes mellitus, family history of cardiac disease and a personal history of cardiac disease) [8,9], accelerated atherosclerosis due to inflammation $[7,10,11]$, and autonomic dysfunction [12-15] can all play a role in the etiopathogenesis.

Exercise has been identified as one of the most important behavioural strategies for cardiovascular disease prevention, and sedentary individuals (like RA sufferers) will benefit by just a slight increase in physical activity [16, 17]. Previous studies in non-RA groups demonstrated that exercise will improve autonomic function (as measured by heart rate variability (HRV)) [18-21]. Abnormal autonomic function 
marked by decreased HRV induces an increased dysrhythmogenic potential $[22,23]$. An article by Routledge et al. in 2010 reviewed HRV modification via exercise therapy in patients with clinical conditions [24]. Similar studies have not been done in the RA population. The aim of the current study was to evaluate the effect of exercise on cardiac autonomic function as measured by short-term HRV in RA patients.

\section{Materials and methods}

This study was a randomised experimental design with a prospective analytical pre-post group comparison. Ethical approval was granted by the Ethical Committee of the Faculty of Health Sciences at the University of Pretoria. Patients in the Pretoria region of South Africa were recruited from private rheumatology practices and state hospital rheumatology clinics.

Patients with RA who conformed to the inclusion and exclusion criteria were invited to an information and orientation meeting. After which, informed consent was signed by all participants. Inclusion criteria included that participants should be females between the age of 30 and 60, with confirmed RA (according to the 1987 American College of Rheumatology criteria) [25], class I or II disease (according to the classification of global functional status in RA) [26], controlled disease (i.e. on stable evidence-based medication for at least 3 months and $\mathrm{DAS}_{28}$ scores of low to moderate activity), and voluntary participation. The exclusion criteria included smoking, known cardiovascular disease, pulmonary disease, diabetes mellitus, neurological disease, use of drugs that can interfere with the autonomic nervous system or the cardiovascular system (anti-hypertensives, antiarrhytmic drugs, diuretics, anti-epileptics, vasodilators, adrenergic inhibitors, sedatives and hypnotics), liver or kidney disease and participation in a physical training programme in the last year.

Colour-coded buttons representing each group (RA control $=$ yellow, RA exercise $=$ blue) were put in a nontransparent bag. Each participant had to draw one of these colour-coded buttons. The administrator allocated the participants into two different groups according to the colour of the buttons, i.e. an exercise group (RAE) and a control group (RAC). The RAE group was required to train two to three times per week, while the RAC group was instructed to continue with their sedentary lifestyle. The programme was conducted over 3 months (12 weeks). All exercise sessions were supervised by a biokineticist (exercise specialist). Exercise intervention consisted of warm-up exercises, strengthening exercises, aerobic exercises and a cooldown period which included stretching. The duration of each session was approximately $45 \mathrm{~min}$.
The warm-up exercise consisted of 5 min of walking, pool jogging or pool noodle cycling. The aerobic exercise lasted for $20 \mathrm{~min}$ at $60-80 \%$ of peak HR doing either treadmill walking, water cycling or water jogging. Flexibility exercise included stretching for each of the major joints (neck stretch, shoulder rolls, lying hamstring stretch, standing hip flexor stretch, calf stretches and pectoral stretch). Five repetitions held for $30 \mathrm{~s}$ each were performed. The strength exercises included chest press, bicep curls, lateral pull-downs, hip extension, leg presses, hamstring curls and hip abduction. The intensity and repetitions of these exercises were increased every second week [27, 28].

Measurements for HRV were done at baseline (onset of the programme) and after 12 weeks (study completion). HRV is a validated, non-invasive method to study the influence of the autonomic nervous system (ANS) on the heart. The parasympathetic and sympathetic nerves act on the intrinsic rhythm, and this causes beat to beat variations in the RR interval on the ECG $[18,29,30]$.

\section{HRV data sampling}

For sampling of the RR-interval data, the participants were instructed not to train for $48 \mathrm{~h}$ before data sampling and to fast from 2200 hours the previous evening. A low protein breakfast (cereal with milk only) was permitted on the morning of testing. No alcohol or caffeine was allowed during the preceding $24 \mathrm{~h}$. Data was sampled in the morning in a quiet setting with a room temperature of about $22^{\circ} \mathrm{C}$. Recordings were made over a period of $20 \mathrm{~min}$.

Each participant put on a Polar 810i strap and transmitter and was then placed in a supine (resting) position for $10 \mathrm{~min}$, breathing spontaneously without talking. This was followed by a 10-min orthostatic stressor with participants standing (stress) in an upright position, with their backs leaning against the wall and their feet apart. RR intervals from a stationary 5-min resting period and a stationary 5-min standing period were used for analyses.

\section{HRV quantification}

Standard Polar software programs with a minimum beat protection zone of six beats per minute and a low filter power were used to remove artefacts in RR-interval data. The data (RR-interval sets) were analysed using software for HRV analysis obtained from the University of Kuopio, Finland. Smoothness priors for trend and Model Eye program settings were used for detrending with an alpha value of 500. The autoregressive model order value was 16 , and the interpolation rate was $4 \mathrm{~Hz}$. The techniques used for the evaluation of HRV from RR-interval data sets were grouped into three categories: time domain, frequency domain and non-linear analysis (Poincarè plot analysis) [29, 31]. As 
there is no gold standard for HRV measurements and no method has been identified as being superior to another, it was decided to use all three techniques as they are complementary to each other [32]. Time domain indicators that were determined included RR interval (the mean of the intervals between successive QRS complexes) and SDRR (the standard deviation of intervals between successive QRS complexes) representing vagal and sympathetic influence, i.e. total variability. RMSSD (root mean square of the standard deviation between RR intervals) and pNN50 (percentage of successive RR interval differences larger than $50 \mathrm{~ms}$ computed over the entire recording) representing pure vagal influence on HRV were also determined [29].

Spectral components analysed with frequency domain analysis included high frequency $(\mathrm{HF}=0.15-0.40 \mathrm{~Hz})$, low frequency $(\mathrm{LF}=0.04-0.15 \mathrm{~Hz})$, HF normalised units $(\mathrm{nu})$, LF (nu) and the LF/HF ratio. The indicators LF/HF, LF (nu) and HF (nu) were used as indicators of autonomic balance or relative power distribution between the sympathetic and parasympathetic branches of the ANS. LF (nu) represents the relative power of the LF component in proportion to the total power minus the VLF component. HF (nu) represents the relative power of the HF component in proportion to the total power minus the VLF component, while LF/HF is used to assess the fractional distribution of power [30]. The Poincarè analysis method produced the indicators SD1 and SD2. SD1 is an indicator of the standard deviation of the immediate, or short-term, RR variability due to parasympathetic efferent (vagal) influence on the sino-atrial node. SD2 is an indicator of the standard deviation of the long-term or slow variability of the heart rate representing global variation [31]. A summary of the HRV analysis techniques, specific HRV indicators and origins of variability is explained in Table 1.

Data analysis

Since most of the variables were skewed, non-parametric tests were conducted. Only two groups (RAE and RAC) were reported on, hence non-parametric Mann-Whitney U tests were performed to determine which dependent variables differed between the two groups. These tests are analogous to independent samples' $t$ tests.

Data analysis was also performed within the two groups (RAE and RAC), comparing pre- and post-intervention measurements. Wilcoxon signed rank tests, which are analogous to paired sample $t$ tests, were used to determine whether there was a statistical improvement within each group.

The conventional $5 \%$ level of significance was specified, and in all instances, the $p$ values of the non-parametric tests are reported. Effect sizes are reported as a standardised measure of the observed effect. For the few variables that did not violate the assumption of normality, a power analysis was also performed.

\section{Results}

At study onset, the RAE group consisted of 24 patients, and the RAC group, of 22 . In the RAE group, five (20.83\%) of the subjects did not complete the study, versus four

Table 1 HRV techniques, HRV indicators and origins of variability

\begin{tabular}{|c|c|c|}
\hline \multirow[t]{4}{*}{$\begin{array}{l}\text { Time domain } \\
\text { analysis }\end{array}$} & $\mathrm{RR}(\mathrm{s})$ & $\begin{array}{l}\text { The mean of the intervals between successive QRS complexes } \\
\text { Result of vagal and sympathetic influence on HRV }\end{array}$ \\
\hline & RRSD (s) & $\begin{array}{l}\text { Standard deviation of intervals between successive QRS complexes } \\
\text { Indicator of vagal and sympathetic influence on HRV (overall HRV) }\end{array}$ \\
\hline & RMSSD (ms) & Root mean square of the standard deviation between RR intervals. Indicator of vagal influence \\
\hline & pNN50 (\%) & $\begin{array}{l}\text { The percentage of successive RR-interval differences larger than } 50 \mathrm{~ms} \text { computed over the entire recording } \\
\text { Indicator of vagal influence on HRV }\end{array}$ \\
\hline \multirow[t]{2}{*}{$\begin{array}{l}\text { Poincarè plot } \\
\text { analysis }\end{array}$} & SD1 (ms) & $\begin{array}{l}\text { Indicator of the standard deviation of the immediate RR variability due to parasympathetic efferent (vagal) } \\
\text { influence on the sino-atrial node }\end{array}$ \\
\hline & $\mathrm{SD} 2(\mathrm{~ms})$ & $\begin{array}{l}\text { Indicator of the standard deviation of the slow variability of the heart rate. It is accepted that this value is } \\
\text { representative of the global variation in HRV }\end{array}$ \\
\hline \multirow{5}{*}{$\begin{array}{l}\text { Frequency } \\
\text { domain analysis }\end{array}$} & $\mathrm{LF}\left(\mathrm{ms}^{2}\right)$ & Indicator of not only sympathetic influence but also a parasympathetic component \\
\hline & $\mathrm{HF}\left(\mathrm{ms}^{2}\right)$ & Indicator of only parasympathetic influence \\
\hline & $\mathrm{LF} / \mathrm{HF}$ & Indicator of autonomic balance \\
\hline & LF (nu) & $\begin{array}{l}\text { LF (normalised units) represents the relative power of the LF component in proportion to the total power } \\
\text { minus the VLF component, i.e. LF / (total power - VLF). }\end{array}$ \\
\hline & HF (nu) & $\begin{array}{l}\text { The HF (normalised units) represents the relative power of the HF component in proportion to the } \\
\text { total power minus the VLF component, i.e. HF / (total power - VLF) }\end{array}$ \\
\hline
\end{tabular}

$L F$ low frequency, $H F$ high frequency, $V L F$ very low frequency, $s$ seconds, $m s$ milliseconds, $\%$ percentage, $m s^{2}$ milliseconds squared, $n u$ normalised units 
$(18.18 \%)$ in the RAC group. Reasons for not completing the study included difficulty to conform to time and frequency of training (four from the RAE group), moved to another town (one from the RAE group), not available for post-intervention measurements due to other commitments (two from the RAC group) and loss of interest (two from the RAC group). Data analyses were only performed on those subjects who completed the study (RAE group 19, RAC group 18) because the study focused on the effect of an exercise intervention and we did not want to bias results by including subjects not completing the study. This sample size is similar to the average sample size of clinical studies that evaluated HRV modification via exercise intervention [24]. Routledge et al. in 2010 evaluated 19 published articles, with the average sample size calculated as 21.2 $( \pm 10.6)$.

Information on age, anthropometric data, disease duration, disease activity, medication used with regard to RA and presence of auto-antibodies is displayed in Table 2 . Subjects were required to stay on the same medication regime for the duration of the study, and no intramuscular or intra-articular corticosteroid injections were allowed. BMI has previously been reported by some authors as a confounding factor $[33,34]$. From the median test, the medians of the BMI did not differ significantly between the two groups $(p=0.127)$ although evidence exists that the distribution of the BMI was not identical across the two groups (Mann-Whitney $\mathrm{U} p=0.05$ ). Regression models that included BMI as a covariate did not support the evidence that BMI is a confounder in this study.

The heart rate variability of the two groups was compared at baseline, and statistics of variables displaying significant initial bias can be viewed in Table 3. At baseline, the RAC group had significantly higher heart rate variability compared to the RAE group for some of the supine variables and most of the standing variables. The RAE group did not show a significant higher variability than the RAC group for any variable pre-intervention.

To compensate for the initial bias between the two groups, the pre-values were subtracted from the postvalues, to assess if the exercise intervention caused changes that favoured any of the two groups. The variables that showed significant differences in changes at study completion are displayed in Table 4. These amounted to medium to large effects [35] and favoured the RAE group in all instances.

To evaluate any changes that occurred within each group from the start of the intervention to the completion,

Table 2 Demographic information on RAE and RAC groups

\begin{tabular}{|c|c|c|c|c|}
\hline \multicolumn{2}{|l|}{ Variable } & RAE group $(n=19)($ mean \pm SD $)$ & RAC group $(n=18)($ mean \pm SD $)$ & $p$ value \\
\hline \multicolumn{2}{|l|}{ Age (years) } & $46.81 \pm 9.23$ & $47.08 \pm 7.05$ & 0.92 \\
\hline \multicolumn{2}{|l|}{ Height (m) } & $1.64 \pm 0.07$ & $1.65 \pm 0.08$ & 0.69 \\
\hline \multicolumn{2}{|l|}{ Weight (kg) } & $69.9 \pm 11.5$ & $80.30 \pm 16.18$ & $0.03 *$ \\
\hline \multicolumn{2}{|l|}{ BMI } & $25.98 \pm 3.53$ & $29.52 \pm 6.04$ & $0.04 *$ \\
\hline \multicolumn{2}{|l|}{ Disease duration (years) } & $4.53 \pm 0.90$ & $3.98 \pm 1.10$ & 0.11 \\
\hline \multicolumn{2}{|l|}{$\mathrm{DAS}_{28}$} & $3.29 \pm 0.72$ & $3.25 \pm 1.08$ & 0.73 \\
\hline \multicolumn{2}{|l|}{ Resting heart rate (bpm) } & $80.60 \pm 8.2$ & $73.36 \pm 7.89$ & $0.01 *$ \\
\hline \multicolumn{5}{|l|}{ RA medication } \\
\hline \multicolumn{2}{|l|}{ Prednisone $^{\mathrm{a}}$} & 10 & 10 & \\
\hline \multirow[t]{4}{*}{ Disease-modifying drugs } & Methotrexate & 18 & 17 & \\
\hline & Sulphasalazine & 0 & 1 & \\
\hline & Chloroquine & 4 & 2 & \\
\hline & Leflunomide & 3 & 2 & \\
\hline \multicolumn{2}{|c|}{ Non-steroidal anti-inflammatory drugs ${ }^{\mathrm{b}}$} & 18 & 17 & \\
\hline \multicolumn{2}{|c|}{ Biologics $^{c}$} & 4 & 6 & \\
\hline \multicolumn{5}{|l|}{ Antibodies } \\
\hline \multicolumn{2}{|l|}{ Positive rheumatoid factor } & 17 & 15 & \\
\hline \multicolumn{2}{|l|}{ Positive anti-CCP } & 9 & 10 & \\
\hline
\end{tabular}

$S D$ standard deviation, $B M I$ body mass index, $D A S$ disease activity score, bpm beats per minute, anti-CCP anti-citrullinated peptide antibodies $* p<0.05$

${ }^{\text {a }}$ Maximum dose of prednisone allowed was $10 \mathrm{mg}$ per day

${ }^{\mathrm{b}}$ Only therapeutic doses allowed

${ }^{\mathrm{c}}$ Medication made from living organisms which are used as a therapeutic agent, e.g. infliximab, etanercept and adalimumab 
Table 3 Statistics of variables displaying initial bias $s$ seconds, bpm beats per minute, $m s$ milliseconds, $\%$ percentage, $m s^{2}$ milliseconds squared, $n u$ normalised units

${ }^{*} p<0.05 ;{ }^{* *} p<0.01$

\begin{tabular}{lcccl}
\hline Variable & RAE group (median) & RAC group (median) & $p$ value & Group favoured \\
\hline Supine (resting) & & & & \\
RR (s) & 0.76 & 0.79 & $0.045^{*}$ & RAC \\
HR (bpm) & 79.17 & 76.12 & $0.049^{*}$ & RAC \\
pNN50 (\%) & 0.00 & 1.70 & $0.022^{*}$ & RAC \\
LF power (ms $\left.{ }^{2}\right)$ & 46.00 & 147.50 & $0.002^{* *}$ & RAC \\
Stress (standing) & & & & \\
SDRR (s) & 0.01 & 0.02 & $0.006^{* *}$ & RAC \\
RMSSD (ms) & 7.50 & 19.25 & $0.002^{* *}$ & RAC \\
pNN50 (\%) & 0.00 & 1.20 & $0.001^{* *}$ & RAC \\
SD1 (ms) & 5.40 & 13.80 & $0.002^{* *}$ & RAC \\
SD2 (ms) & 28.35 & 57.80 & $0.001^{* *}$ & RAC \\
LF power (ms $\left.{ }^{2}\right)$ & 38.50 & 174.50 & $<0.001^{* *}$ & RAC \\
HF power (ms $\left.{ }^{2}\right)$ & 5.00 & 38.00 & $<0.001^{* *}$ & RAC \\
LF (nu) & 86.30 & 73.85 & $0.042^{*}$ & RAC \\
LF/HF & 7.55 & 3.68 & $0.020^{*}$ & RAC \\
\hline
\end{tabular}

Wilcoxon signed rank tests were performed. The RAE group showed statistical significant changes for SDRR in the supine position and for SDRR and pNN50 in the stress position. The RAC group showed statistical significant changes for SDRR (supine), SDRR (stress), RMSSD (stress), pNN50 (stress), SD1 (stress) and LF/HF (stress). The variables for both groups are displayed in Table 5 and again amounted to medium to large effects [35]. Although not statistically significant at the specified $5 \%$ level of significance, there was moderate evidence $(\alpha<0.10)$ of change in many variables (RAE group: RR (supine), LF (nu) (supine), RR (stress), HR (stress), RMSSD (stress), $\mathrm{SD} 1$ (stress), SD2 (stress), LF ( $\mathrm{ms}^{2}$ ) (stress); RAC group: $\mathrm{HF}\left(\mathrm{ms}^{2}\right)$ (stress), HF (nu) (stress)). Within the RAE group, the variables mostly improved, contrary to the RAC group where the change was mostly a deterioration (i.e. less parasympathetic activity and an increased sympathetic drive in the RAC group at study completion).

\section{Discussion}

This study demonstrates that exercise intervention has a positive effect on autonomic function of RA patients, as measured by short-term heart rate variability. Comparing the exercise group to the control group at baseline, the control group showed better heart rate variability. However, at study completion, this change was in favour of the exercise group who then showed better heart rate variability. Our results are confirmed by that of Jurca et al. in 2004 who, after 8 weeks of moderate exercise training in females, showed improved vagal modulation of heart rate on 10min resting ECGs [36].

Many previous studies done on diseased populations to evaluate the effect of short-term exercise intervention on short-term HRV modification assessed only supine variables [37-43]. Sandercock et al. in 2007 observed significant increases in the supine RR interval, SDRR, LF(ln) and HF
Table 4 Variables that showed significant differences in changes (post-value minus prevalue) between the RAE and RAC groups after intervention

$s$ seconds, $b p m$ beats per minute, $m s$ milliseconds, $\%$ percentage $* p<0.05 ; * * p<0.01$

\begin{tabular}{|c|c|c|c|c|c|}
\hline \multirow[t]{2}{*}{ Variable } & \multicolumn{2}{|l|}{ Differences } & \multirow[t]{2}{*}{$p$ value } & \multirow[t]{2}{*}{ Effect size (power) } & \multirow[t]{2}{*}{ Group favoured } \\
\hline & RAE group & RAC group & & & \\
\hline \multicolumn{6}{|c|}{ Supine (resting) } \\
\hline $\mathrm{RR}(\mathrm{s})$ & 0.07 & -0.01 & $0.022 *$ & $0.52(0.60)$ & RAE \\
\hline HR (bpm) & -6.79 & 1.47 & $0.029 *$ & $0.49(0.61)$ & RAE \\
\hline \multicolumn{6}{|c|}{ Stress (standing) } \\
\hline $\mathrm{RR}(\mathrm{s})$ & 0.03 & 0.00 & $0.033^{*}$ & 0.47 & RAE \\
\hline HR (bpm) & -6.91 & -0.31 & $0.021 *$ & 0.52 & RAE \\
\hline RMSSD (ms) & 1.40 & -3.90 & $0.012 *$ & 0.59 & RAE \\
\hline pNN50 (\%) & 0.00 & -0.20 & $0.005^{* *}$ & 0.66 & RAE \\
\hline SD1 (ms) & 0.90 & -2.80 & $0.011^{*}$ & 0.59 & RAE \\
\hline $\mathrm{SD} 2(\mathrm{~ms})$ & 3.40 & -3.40 & $0.050 *$ & 0.42 & RAE \\
\hline
\end{tabular}


Table 5 HRV variables that showed a change from pre- to post-intervention within the RAE and RAC groups

\begin{tabular}{|c|c|c|c|c|c|c|}
\hline & Variable & Median pre-value & Median post-value & $p$ value & Effect size (power) & $\mathrm{I} / \mathrm{D}$ \\
\hline \multicolumn{7}{|l|}{ RAE group } \\
\hline Supine (resting) & SDRR (s) & $\left(0.017^{\mathrm{a}}\right) 0.02$ & $\left(0.022^{\mathrm{a}}\right) 0.02$ & $0.022 *$ & 0.52 & I \\
\hline \multirow[t]{2}{*}{ Stress (standing) } & SDRR (s) & 0.01 & 0.02 & $0.002 * *$ & 0.74 & I \\
\hline & pNN50 (\%) & 0.00 & 0.00 & $0.014 *$ & 0.57 & $\sim$ \\
\hline \multicolumn{7}{|l|}{ RAC group } \\
\hline Supine (resting) & SDRR (s) & 0.02 & 0.03 & $0.049^{*}$ & $0.41(0.30)$ & I \\
\hline \multirow[t]{5}{*}{ Stress (standing) } & SDRR (s) & 0.02 & 0.03 & $0.013 *$ & $0.54(0.83)$ & I \\
\hline & RMSSD (ms) & 19.25 & 13.30 & $0.038 *$ & $0.43(0.66)$ & $\mathrm{D}$ \\
\hline & pNN50 (\%) & 1.20 & 0.50 & $0.035^{*}$ & 0.44 & $\mathrm{D}$ \\
\hline & $\mathrm{SD} 1$ (ms) & 13.80 & 9.60 & $0.036^{*}$ & $0.44(0.69)$ & $\mathrm{D}$ \\
\hline & $\mathrm{LF} / \mathrm{HF}$ & 3.68 & 5.82 & $0.042^{*}$ & $0.42(0.61)$ & $\mathrm{D}$ \\
\hline
\end{tabular}

$s$ seconds, \% percentage, $m s$ milliseconds, $I$ improved on median values, $D$ deterioration on median values

$* p<0.05 ; * * p<0.01$

${ }^{\text {a }}$ Reflects true value where rounded off value could be misleading

(ln) in a group of patients, who had coronary artery bypass grafting and angioplasty following myocardial infarction (MI), after 8 weeks of cardiac rehabilitation [37]. Malfatto in 1996 also showed significant increases for RR interval, SDRR, RMSSD, pNN50 and HF but a decline in LF in patients who followed a training programme after MI [38]. On the other hand, Oya et al. in 1999 could not show any significant difference in HRV in MI patients after a 3-month training programme [39]. Figueroa et al. in 2007 observed a significant increase in LF and HF in a 16-week study in obese women with and without type 2 diabetes mellitus [43]. All the above mentioned studies (except that of Oya et al.) thus showed increased vagal tone (HF, RMSSD, pNN50), but the LF variable seems to be difficult to interpret with changes in different directions in the different studies.

In the present study, only the RR interval increased significantly in the supine position, while the other variables did not show significant changes in favour of the exercise group. It is not clear why increased vagal tone was not picked up in the supine position in our analyses; however, Iwasaki et al. in 2003 did a study where HF and RR interval increased early in the training of young previously sedentary subjects, but at study completion after 1 year, HF regressed towards initial values whereas RR interval uniformly increased. They suggested that initial increases may be due to higher vagal modulation, while other factors such as heart geometry may play a role in further adaptation [44].

It was mainly the variables obtained in the standing position that were affected favourably in our exercise group in comparison to the control group. Zoppini et al. in 2007 found similar results in a study on patients with type 2 diabetes mellitus where they showed significant changes in standing, but not supine variables after a 6-month exercise programme [45]. In the current study, the changes reflected a greater effect on increased vagal rather than on decreased sympathetic influence. Buch et al. in 2002 pointed out that patients may have a better survival advantage with enhanced vagal tone. Reasons offered were that greater vagal influence will decrease heart rate and myocardial contractility (i.e. due to less workload and oxygen consumption), hinder sympathetic influence on the sinus node and reduce the risk of ventricular dysrhythmias [46]. Therefore, improving the vagal tone in RA patients may be an instrument to decrease their cardiovascular morbidity and mortality.

De Meersman commented that "Ultimately, all of these cardiovascular diseases are associated with a common denominator, namely a perturbed autonomic balance. It is tempting, therefore, to hypothesise that preservation of cardiac autonomic function by lifestyle or interventions should be associated with a marked reduction in the risk of cardiovascular disease and death" [47]. Exercise intervention appears to have an advantageous effect on cardiac autonomic function in RA patients as measured by short-term heart rate variability. Especially, vagal modulation seems to improve, and this can lead to improved cardiac health in a patient group already suffering from impaired lifestyle due to joint pain and other complications following a diagnosis of RA.

Limitations of the study

Unfortunately, this study suffers from the implication of low statistical power, due to the unavoidable small sample size; therefore, effect sizes were reported to quantify the effectiveness of the intervention. Similar studies, e.g. on diabetic $[43,45]$ and cardiac patients $[38,40,41]$, had equal or even less participants. 
Heart rate variability was the only tool used to assess the function of the autonomic nervous system. Including tests such as analysis of blood pressure variability may add information and support results obtained by HRV analysis.

Acknowledgments We thank Brenda Weder and Ria Smuts for their technical assistance, our patients who, through their dedication, made it possible to complete the study and the staff of the Medical Library at the University of Pretoria for their assistance in scrutinising the literature and finding relevant articles.

Disclosures None.

Open Access This article is distributed under the terms of the Creative Commons Attribution License which permits any use, distribution, and reproduction in any medium, provided the original author(s) and the source are credited.

\section{References}

1. Stenstrom CH, Minor MA (2003) Evidence for the benefit of aerobic and strengthening exercise in rheumatoid arthritis. Arthritis Rheum 49:428-434

2. Van Den Ende CH, Vliet Vlieland TP, Munneke M, Hazes JM (2000) Dynamic exercise therapy for rheumatoid arthritis. Cochrane Database Syst Rev (2):CD000322

3. Janse van Rensburg DC, Fletcher L, Viljoen M, Coertzen C, Grant CC, Ramagole DA et al (2010) Efficacy of an exercise programme on the functional capacity and disease activity in females with rheumatoid arthritis. SA Orthop J 9:34-43

4. Metsios GS, Stavropoulos-Kalinoglou A, Veldhuijzen van Zanten JJ, Treharne GJ, Panoulas VF, Douglas KM et al (2008) Rheumatoid arthritis, cardiovascular disease and physical exercise: a systematic review. Rheumatology (Oxford) 47:239-248

5. John H, Kitas G, Toms T, Goodson N (2009) Cardiovascular comorbidity in early rheumatoid arthritis. Best Pract Res Clin Rheumatol 23:71-82

6. Nurmohamed MT (2009) Cardiovascular risk in rheumatoid arthritis. Autoimmun Rev 8:663-667

7. Gabriel SE (2010) Heart disease and rheumatoid arthritis: understanding the risks. Ann Rheum Dis 69(Suppl 1):i61-64

8. Maradit-Kremers H, Crowson CS, Nicola PJ, Ballman KV, Roger VL, Jacobsen SJ et al (2005) Increased unrecognized coronary heart disease and sudden deaths in rheumatoid arthritis: a population-based cohort study. Arthritis Rheum 52:402-411

9. Myasoedova E, Davis JM 3rd, Crowson CS, Gabriel SE (2010) Epidemiology of rheumatoid arthritis: rheumatoid arthritis and mortality. Curr Rheumatol Rep 12:379-385

10. Kao AH, Wasko MC, Krishnaswami S, Wagner J, Edmundowicz $\mathrm{D}$, Shaw $\mathrm{P}$ et al (2008) C-reactive protein and coronary artery calcium in asymptomatic women with systemic lupus erythematosus or rheumatoid arthritis. Am J Cardiol 102:755-760

11. Rho YH, Chung CP, Oeser A, Solus J, Asanuma Y, Sokka T et al (2009) Inflammatory mediators and premature coronary atherosclerosis in rheumatoid arthritis. Arthritis Rheum 61:1580-1585

12. Waldburger JM, Firestein GS (2010) Regulation of peripheral inflammation by the central nervous system. Curr Rheumatol Rep 12:370-378

13. Tracey KJ (2002) The inflammatory reflex. Nature 420:853-859

14. Borovikova LV, Ivanova S, Zhang M, Yang H, Botchkina GI, Watkins LR et al (2000) Vagus nerve stimulation attenuates the systemic inflammatory response to endotoxin. Nature $405: 458$ 462

15. Bernik TR, Friedman SG, Ochani M, DiRaimo R, Ulloa L, Yang H et al (2002) Pharmacological stimulation of the cholinergic antiinflammatory pathway. J Exp Med 195:781-788

16. Duscha BD, Slentz CA, Johnson JL, Houmard JA, Bensimhon DR, Knetzger KJ et al (2005) Effects of exercise training amount and intensity on peak oxygen consumption in middle-age men and women at risk for cardiovascular disease. Chest 128:2788-2793

17. Shephard RJ, Balady GJ (1999) Exercise as cardiovascular therapy. Circulation 99:963-972

18. Aubert AE, Seps B, Beckers F (2003) Heart rate variability in athletes. Sports Med 33:889-919

19. Madden KM, Levy WC, Stratton JK (2006) Exercise training and heart rate variability in older adult female subjects. Clin Invest Med 29:20-28

20. Freeman JV, Dewey FE, Hadley DM, Myers J, Froelicher VF (2006) Autonomic nervous system interaction with the cardiovascular system during exercise. Prog Cardiovasc Dis 48:342-362

21. Reland S, Ville NS, Wong S, Senhadji L, Carre F (2004) Does the level of chronic physical activity alter heart rate variability in healthy older women? Clin Sci (Lond) 107:29-35

22. Jouven X, Empana JP, Schwartz PJ, Desnos M, Courbon D, Ducimetiere P (2005) Heart-rate profile during exercise as a predictor of sudden death. N Engl J Med 352:1951-1958

23. Frolkis JP, Pothier CE, Blackstone EH, Lauer MS (2003) Frequent ventricular ectopy after exercise as a predictor of death. N Engl J Med 348:781-790

24. Routledge FS, Campbell TS, McFetridge-Durdle JA, Bacon SL (2010) Improvements in heart rate variability with exercise therapy. Can J Cardiol 26:303-312

25. Arnett FC, Edworthy SM, Bloch DA, McShane DJ, Fries JF, Cooper NS et al (1988) The American Rheumatism Association 1987 revised criteria for the classification of rheumatoid arthritis. Arthritis Rheum 31:315-324

26. Hochberg MC, Chang RW, Dwosh I, Lindsey S, Pincus T, Wolfe F (1992) The American College of Rheumatology 1991 revised criteria for the classification of global functional status in rheumatoid arthritis. Arthritis Rheum 35:489-502

27. Iversen MD (2002) Physical therapy for management of RA: rehabilitation measures are most effective when started early. J Muscoskel Med 19:352-358

28. Armstrong L, Balady GJ, Berry MJ (2006) ACSM guidelines for exercise testing and prescription Lippincott, Philadelphia

29. Task Force of the European Society of Cardiology and the North American Society of Pacing and Electrophysiology (1996) Heart rate variability: standards of measurement, physiological interpretation and clinical use. Circulation 93:1043-1065

30. Montano N, Porta A, Cogliati C, Costantino G, Tobaldini E, Casali $\mathrm{KR}$ et al (2009) Heart rate variability explored in the frequency domain: a tool to investigate the link between heart and behavior. Neurosci Biobehav Rev 33:71-80

31. Mourot L, Bouhaddi M, Perrey S, Rouillon JD, Regnard J (2004) Quantitative Poincare plot analysis of heart rate variability: effect of endurance training. Eur J Appl Physiol 91:79-87

32. Lahiri MK, Kannankeril PJ, Goldberger JJ (2008) Assessment of autonomic function in cardiovascular disease: physiological basis and prognostic implications. J Am Coll Cardiol 51:1725-1733

33. Kim JA, Park YG, Cho KH, Hong MH, Han HC, Choi YS et al (2005) Heart rate variability and obesity indices: emphasis on the response to noise and standing. J Am Board Fam Pract 18(2):97-103

34. Karason K, Molgaard H, Wikstrand J, Sjostrom L (1999) Heart rate variability in obesity and the effect of weight loss. Am J Cardiol 83(8):1242-1247

35. Field AP (2009) Discovering statistics using SPSS: (and sex and drugs and rock 'n' roll), 3rd edn. Sage, Los Angeles 
36. Jurca R, Church TS, Morss GM, Jordan AN, Earnest CP (2004) Eight weeks of moderate-intensity exercise training increases heart rate variability in sedentary postmenopausal women. Am Heart J 147:e21

37. Sandercock GR, Grocott-Mason R, Brodie DA (2007) Changes in short-term measures of heart rate variability after eight weeks of cardiac rehabilitation. Clin Auton Res 17:39-45

38. Malfatto G, Facchini M, Bragato R, Branzi G, Sala L, Leonetti G (1996) Short and long term effects of exercise training on the tonic autonomic modulation of heart rate variability after myocardial infarction. Eur Heart J 17:532-538

39. Oya M, Itoh H, Kato K, Tanabe K, Murayama M (1999) Effects of exercise training on the recovery of the autonomic nervous system and exercise capacity after acute myocardial infarction. Jpn Circ J 63:843-848

40. Selig SE, Carey MF, Menzies DG, Patterson J, Geerling RH, Williams $\mathrm{AD}$ et al (2004) Moderate-intensity resistance exercise training in patients with chronic heart failure improves strength, endurance, heart rate variability, and forearm blood flow. J Card Fail 10:21-30

41. Lucini D, Milani RV, Costantino G, Lavie CJ, Porta A, Pagani M (2002) Effects of cardiac rehabilitation and exercise training on autonomic regulation in patients with coronary artery disease. Am Heart J 143:977-983
42. Iellamo F, Legramante JM, Massaro M, Raimondi G, Galante A (2000) Effects of a residential exercise training on baroreflex sensitivity and heart rate variability in patients with coronary artery disease: a randomized, controlled study. Circulation 102:25882592

43. Figueroa A, Baynard T, Fernhall B, Carhart R, Kanaley JA (2007) Endurance training improves post-exercise cardiac autonomic modulation in obese women with and without type 2 diabetes. Eur J Appl Physiol 100:437-444

44. Iwasaki K, Zhang R, Zuckerman JH, Levine BD (2003) Doseresponse relationship of the cardiovascular adaptation to endurance training in healthy adults: how much training for what benefit? J Appl Physiol 95:1575-1583

45. Zoppini G, Cacciatori V, Gemma ML, Moghetti P, Targher G, Zamboni $C$ et al (2007) Effect of moderate aerobic exercise on sympatho-vagal balance in type 2 diabetic patients. Diabet Med 24:370-376

46. Buch AN, Coote JH, Townend JN (2002) Mortality, cardiac vagal control and physical training-what's the link? Exp Physiol 87:423-435

47. De Meersman RE, Stein PK (2007) Vagal modulation and aging. Biol Psychol 74:165-173 